\title{
Amygdala/hippocampal activation during the menstrual cycle: Evidence for lateralization of effects across different tasks
}

\author{
Nina Lisofsky*, Ulman Lindenberger, Simone Kühn \\ Max Planck Institute for Human Development, Berlin, Germany
}

\section{A R T I C L E I N F O}

\section{Article history:}

Received 29 July 2014

Received in revised form

1 December 2014

Accepted 2 December 2014

Available online 8 December 2014

\section{Keywords:}

Menstrual cycle

Hormones

fMRI

Hippocampus

Amygdala

\begin{abstract}
A B S T R A C T
Variations in hormonal levels between the follicular and the luteal phase of the female menstrual cycle are associated with variations in emotional and cognitive aspects of behavior. The functional neural correlates of these cycle-related variations have been explored in previous neuroimaging studies. We summarize the existing findings of functional magnetic resonance imaging (fMRI) studies to identify regions of increased brain activation in the follicular or luteal phases of the cycle that are concordant across studies. Eleven fMRI studies reporting coordinates of higher brain activation in one of the two main cycle phases were included in the analysis. Activation likelihood estimation was used to determine concordance. We found higher left amygdala/hippocampal activation during the luteal phase and higher right amygdala/hippocampal activation during the follicular phase. Additionally, the anterior cingulate cortex and temporal pole showed increased activation during the luteal phase and the superior temporal gyrus during the follicular phase. The observed pattern of cycle-dependent functional lateralization of the amygdala/hippocampal complex is consistent with findings on cycle-related behavioral variations and on sex differences in lateralization of activity in amygdala and hippocampus.
\end{abstract}

(c) 2014 Elsevier Ltd. All rights reserved.

\section{Introduction}

Hormonal differences, as they naturally occur during the female menstrual cycle, are known to have widespread effects on cognition and emotion in animals as well as humans (Derntl et al., 2008; Lacreuse et al., 2001; Mordecai et al., 2008; Rosenberg and Park, 2002; Silverman and Phillips, 1993; Stackman et al., 1997). Although a multitude of studies point to differences in brain function across the menstrual cycle and a growing number of functional magnetic resonance imaging (fMRI) studies investigate dissociable neural activation patterns between cycle phases, a cumulative analysis of the existing literature on menstrual cycle related functional variability in women is lacking.

During the female cycle, the sex hormones estrogen and progesterone fluctuate at a frequency of only a few days in female rats and about a month in human females. The first half of the menstrual cycle is called the follicular phase and the second half the luteal phase. The follicular phase starts with the menstruation, which is accompanied by low estrogen as well as progesterone levels (Sherman and Korenman, 1975). Estrogen and progesterone

Abbreviations: ACC, anterior cingulate cortex; ALE, activation likelihood estimation; MNI, Montreal Neurological Institute; fMRI, functional magnetic resonance imaging; MR, magnetic resonance; STG, superior temporal gyrus

* Corresponding author.

E-mail address: lisofsky@mpib-berlin.mpg.de (N. Lisofsky). values are typically lower in the first, follicular phase, compared to the luteal phase. However estrogen begins to rise during the second half of the follicular phase and peaks shortly before ovulation in the middle of the cycle. During the second, post-ovulation and pre-menstruation phase of the cycle, estrogen and progesterone levels are relatively high and falling levels of progesterone in the end of the luteal phase elicit the next menstruation. Apart from estrogen and progesterone, two additional hormones play a role in the female cycle, namely, luteinizing hormone (LH) and follicle stimulating hormone (FSH). Both reach their peak around ovulation (Sherman and Korenman, 1975).

Researchers have focused on different cycle phases to assess the influence of the female gonadal hormones on the brain and behavior. In large part previous studies have compared the follicular with the luteal phase, to contrast a low estrogen/progesterone phase with a high estrogen/progesterone phase. It has to be considered that this only holds for the early follicular phase (about the first 10 days of the cycle) and not for the late follicular phase (a few days before ovulation). When measurements take place during the late follicular phase, it is not clear whether the observed effects are due to high levels of both hormones compared to low levels of both, or to the effect of elevated estrogen levels accompanied by high progesterone levels in the luteal phase vs high estrogen levels only in the follicular phase. Another problem frequently encountered in the present literature is that not all studies tested the presence of ovulation before measuring participants in 
the luteal phase and thereby potentially including non-ovulatory cycles in their assessment.

Apart from these limitations of previous studies, there is evidence for traceable effects of cycle-related estrogen and progesterone variations in human and non-human females on psychological functions coming from different research areas. We will first summarize the animal literature, than briefly describe behavioral differences that have been related to hormonal change in women and last, describe studies looking at differences in functional brain activation across the human menstrual cycle.

Animal research has led to a number of findings revealing widespread effects of estrogen and progesterone variation across the female cycle on neural plasticity in the brain and thus on behavior. The limbic structures have been found to be specifically sensitive to those hormonal shifts in animals. Higher levels of estrogen have been associated with profound increases in different structural and functional characteristics of the rat's hippocampus (Pawluski et al., 2009; Spencer et al., 2008). Besides neurogenesis in the dentate gyrus of the hippocampus, rise in endogenous estrogen is followed by the formation of new synapses and an increased sensitivity of these synapses to NMDA receptor-mediated input (McEwen and Milner, 2007; Woolley and McEwen, 1993; Woolley et al., 1997, 1996). It is important to notice, that the effects of estrogen on the brain are altered by progesterone levels and might vary between species (Pawluski et al., 2009). Apart from the hippocampus, comparable cycle-related differences in spine-density were also observed in the amygdala (Rasia-Filho et al., 2004). Estrogen-receptors and a number of genomic as well as nongenomic pathways have been proposed as physiological mechanisms underlying these effects (Rasia-Filho et al., 2004; Spencer et al., 2008). In addition, estrogen-related brain plasticity has been linked to measurable behavioral differences between cycle phases. Especially memory and spatial navigation performance have been shown to differ across the estrous cycle in female rats (for an overview, see Korol (2004)).

Informed by these animal findings it has been hypothesized that hippocampal- and amygdala-related psychological functions in humans are likewise affected by fluctuating estrogen and progesterone levels. Cognitive abilities, such as spatial and verbal skills were targets of that line of research and both functions have previously been related to medial temporal lobe activity (Fernández et al., 1998; Ino et al., 2004; Kühn and Gallinat, 2014). Additionally, perception of emotional stimuli and pain perception, functions that have been related to the amygdala, were studied in relation to the menstrual cycle. Regarding the cognitive domains, a multitude of studies have investigated differences in performance in spatial and verbal abilities between cycle phases (Fernández et al., 2003; Hampson, 1990; Hausmann et al., 2000; Konrad et al., 2008; Maki et al., 2002; Mordecai et al., 2008; Pletzer et al., 2011; Rosenberg and Park, 2002; Rumberg et al., 2010; Schöning et al., 2007). Although some studies failed to find performance differences (e.g., Rumberg et al., 2010), a number of studies reported improved verbal- or decreased spatial abilities in women during the luteal phase when compared to the follicular phase (Hampson, 1990; Hausmann et al., 2000; Maki et al., 2002; Pletzer et al., 2011; Rosenberg and Park, 2002; Schöning et al., 2007). Some of these studies did directly relate estrogen and progesterone concentration to those performance differences. For instance, Maki et al, (2002) found positive correlations between verbal fluency and negative correlations between mental rotation as well as perceptual priming and fluctuating estrogen levels in young women. Next to cognitive paradigms, changes in mood as well as pain perception were targets of menstrual-cycle research. Although several studies report changes in vulnerability to mood disorders in relation to the menstrual cycle (Endicott, 1993; Moos et al., 1969), no concordant pattern of increased negative mood in specific cycle phases emerged in the general population (Romans et al., 2012). More consistent seem to be changes in pain sensitivity across the cycle that were investigated in a number of experimental paradigms. Choi et al. (2006) for instance report, that women rate pain and feelings of unpleasantness higher during the luteal than the follicular phase. For a review on the cognitive, sensory and emotional changes that have been associated with the menstrual cycle in the literature, see Farage et al. (2008).

In the last decades, a growing number of studies shed light on differential brain activity across the human female cycle. The studies searched for varying neural responses elicited by the same task performed in different cycle phases. Significant effects were found in a broad range of brain regions, including frontal and prefrontal cortex, cingulate cortex, temporal and parietal cortex, occipital cortex, putamen, thalamus, hippocampus/parahippocampal gyrus and amygdala and in a variety of cognitive tasks (Craig et al., 2008; Fernández et al., 2003; Konrad et al., 2008; Pletzer et al., 2011; Rumberg et al., 2010; Schöning et al., 2007). Even in the absence of performance differences, some studies found distinguishable neural activations for the same tasks measured in different cycle phases, such as semantic or visuospatial tasks, while for other tasks, such as perceptual tasks, those differences were not observed (Fernández et al., 2003; Schöning et al., 2007). Some studies could directly link the recruitment of specific brain regions to estrogen and/or progesterone levels (Craig et al., 2008; Fernández et al., 2003), providing even stronger evidence for the interaction of hormonal variation and brain function.

Researchers did not only focus on activity elicited by cognitive tasks, but also on processing of specific (for example emotional or rewarding) stimuli that lead to dissimilar functional brain activation across different cycle phases as well. Amygdala activity elicited by emotional stimuli is one example. Whereas some authors reported higher amygdala reactivity during the luteal phase when compared to the follicular phase (Andreano and Cahill, 2010; Gingnell et al., 2012), others observed an effect in the opposite direction when inducing stress by means of aversive video clips (Ossewaarde et al., 2010) or using arousive negative stimuli (Goldstein et al., 2005). Additional neural substrates involved in affective processing, such as the orbitofrontal cortex, also seem to vary in their activity by cycle phase (Protopopescu et al., 2005).

Another strand of fMRI research on the menstrual cycle deals with the question whether lateralization and hemispheric asymmetry is related to gonadal hormones. Based on findings of differences in hemispheric asymmetry between men and women (mostly showing reduced asymmetry in women compared to men; Hausmann and Bayer, 2010) some fMRI studies have examined functional asymmetries and hemispheric lateralization as a function of cycle phase (Dietrich et al., 2001; Fernández et al., 2003; Weis et al., 2008, 2011). The specific impact of estrogen and progesterone on hemispheric lateralization is still unclear, although a number of behavioral studies attempted to examine lateralization effects in different cycle phases (for an overview, see Hausmann and Bayer (2010)). Hausmann and Güntürkün proposed a hypothesis of sex-hormone-modulated cortical interaction (see Hausmann and Bayer, 2010, p. 264 ff). This model took the results of several behavioral and neuropsychological studies, including the fMRI studies mentioned above, into account. According to the authors, estrogen and progesterone both influence hemispheric asymmetries in brain activation. The authors propose that hormones modulate interhemispheric interaction by affecting interhemispheric inhibition, interhemispheric transport time and interhemispheric integration. High hormonal levels during the luteal phase might reduce interhemispheric inhibition, leading to functional hemispheric decoupling and reduced asymmetries between the hemispheres.

To summarize, there is growing evidence that estrogen and 
Table 1

Studies included in the analysis.

\begin{tabular}{|c|c|c|c|c|c|c|c|c|c|c|}
\hline First author, year & $\begin{array}{l}\text { Number of } \\
\text { subjects }\end{array}$ & Age of subjects & $\begin{array}{l}\text { Handedness of } \\
\text { subjects }\end{array}$ & Contrast $^{\mathrm{a}}$ & fMRI paradigm/task & Stimuli & Timepoint & $\begin{array}{l}\text { Hormonal } \\
\text { assessment }\end{array}$ & $\begin{array}{l}\text { Ovulation } \\
\text { confirmed }\end{array}$ & $\begin{array}{l}\text { Number of } \\
\text { foci }\end{array}$ \\
\hline Amin et al., 2006 & 14 & $25.4 \pm 6.7$ & Right & $\mathrm{L}>\mathrm{F}$ & $\begin{array}{l}\text { Go/NoGo task - affective re- } \\
\text { sponse inhibition }\end{array}$ & $\begin{array}{l}\text { Words from Affective } \\
\text { Norms for English } \\
\text { Words }\end{array}$ & $\begin{array}{l}\text { EF (d 0-7) L (postovulatory } \\
\text { d 6-10) }\end{array}$ & Blood: E,P, LH & Yes & $1(\mathrm{~L})$ \\
\hline $\begin{array}{l}\text { Bannbers et al., } \\
2012\end{array}$ & $\begin{array}{l}13 \text { (healthy } \\
\text { controls) }\end{array}$ & $34.9 \pm 8.6$ & Right & $\mathrm{F}>\mathrm{L}$ & $\begin{array}{l}\text { Go/NoGo task - response } \\
\text { inhibition }\end{array}$ & Letters & $\begin{array}{l}\mathrm{MF} \text { (postmenstrual d 6-12) } \\
\mathrm{LL} \text { (postovulatory d 8-13) }\end{array}$ & E, P, LH & Yes & $2(F)$ \\
\hline Choi et al., 2006 & 18 & $23.11 \pm 1.91$ & Right & Both & $\begin{array}{l}\text { Pain and painrelated } \\
\text { unpleasentness }\end{array}$ & $\begin{array}{l}30 \mathrm{~s} \text { finger immer- } \\
\text { sion stimulation at } \\
48^{\circ} \mathrm{C} \text { (pain) }\end{array}$ & $F(d$ 2-13) L (d 16-26) & $\begin{array}{l}\text { Blood: E, P, } \\
\text { testosterone }\end{array}$ & Prog & $18(\mathrm{~F}) 9(\mathrm{~L})$ \\
\hline Dreher et al., 2007 & 11 & 29 range $=6$ & Right & Both & Monetary reward & Slot machines & $\begin{array}{l}\text { MF (d 4-8) L (d 6-10 after } \\
\text { LH surge) }\end{array}$ & $\begin{array}{l}\text { Urine: LH blood: } \mathrm{E}, \\
\text { P }\end{array}$ & Yes & $10(\mathrm{~F}) 5(\mathrm{~L})$ \\
\hline Frank et al., 2010 & 12 & $22(18-35)$ & Right & $\mathrm{F}>\mathrm{L}$ & $\begin{array}{l}\text { Food pictures with differing ca- } \\
\text { loric content }\end{array}$ & Visual food cues & $\begin{array}{l}\mathrm{F} \text { (mean } 3.4 \mathrm{~d} \text { before LH- } \\
\text { peak) } \mathrm{L} \text { (mean } 4.7 \mathrm{~d} \text { before } \\
\text { menses) }\end{array}$ & Urine: LH & Yes & $3(\mathrm{~F})$ \\
\hline $\begin{array}{l}\text { Gizewski et al., } \\
2006\end{array}$ & 22 & $27(20-35)$ & Right & $\mathrm{L}>\mathrm{F}$ & Processing of erotic stimuli & $\begin{array}{l}\text { Erotic video } \\
\text { sequences }\end{array}$ & Menses ML & & No & $1(\mathrm{~L})$ \\
\hline $\begin{array}{l}\text { Protopopescu et al., } \\
2005\end{array}$ & 12 & $28(22-35)$ & Right & Both & $\begin{array}{l}\text { Neutral and negative stimuli - } \\
\text { emotion processing }\end{array}$ & Words & $\begin{array}{l}F(8-12 d) L(1-5 d \text { before } \\
\text { onset of menses) }\end{array}$ & Urine: LH & Yes & $4(\mathrm{~F}) 1(\mathrm{~L})$ \\
\hline Roberts et al., 2008 & 15 & $22.5(18-39)$ & Right & $\mathrm{F}>\mathrm{L}$ & Go/NoGo - cognitive control & $\begin{array}{l}\text { Male and female at- } \\
\text { tractive faces }\end{array}$ & $\mathrm{F}(\mathrm{d} 10-14) \mathrm{L}(\mathrm{d} 21-24)$ & Urine: LH & Yes & $2(F)$ \\
\hline Rupp et al., 2009 & 10 & $25.15 \pm 1.91$ & Not reported & $\mathrm{F}>\mathrm{L}$ & $\begin{array}{l}\text { Evaluation of the stimuli as po- } \\
\text { tential sex partners (men) or } \\
\text { potential rentals (houses) }\end{array}$ & $\begin{array}{l}\text { Pictures of men and } \\
\text { houses }\end{array}$ & $\begin{array}{l}\mathrm{LF}(\mathrm{d} \text { 10-12) L (d 19-23 } \\
\text { after menses) }\end{array}$ & $\begin{array}{l}\text { Blood: } \mathrm{E}, \mathrm{P} \\
\text { testosterone }\end{array}$ & Prog & $1(\mathrm{~F})$ \\
\hline $\begin{array}{l}\text { Schöning et al., } \\
2007\end{array}$ & 12 & $32 \pm 5.63$ & Right & Both & $\begin{array}{l}\text { Mental rotation - visuospatial } \\
\text { working memory }\end{array}$ & $\begin{array}{l}\text { 3D objects from } \\
\text { standard Mental Ro- } \\
\text { tation Test }\end{array}$ & $\begin{array}{l}\text { EF (d 1-3) ML (individ. cy- } \\
\text { cle lengths }-7 \pm 2 \text { d) }\end{array}$ & $\begin{array}{l}\text { Blood: E, P; LH, } \\
\text { FSH, testosterone }\end{array}$ & Yes & $2(\mathrm{~F}) 13(\mathrm{~L})$ \\
\hline Weis et al., 2011 & 14 & $26.83 \pm 4.98$ & Right & $\mathrm{F}>\mathrm{L}$ & $\begin{array}{l}\text { Shape comparison - spatial } \\
\text { cognition }\end{array}$ & Irregular polygons & $\begin{array}{l}\text { Menstrual phase (d 1-3) F } \\
\text { (d 9-11) L (d 21-23) }\end{array}$ & Blood: E, P & Prog & $2(\mathrm{~F})$ \\
\hline
\end{tabular}

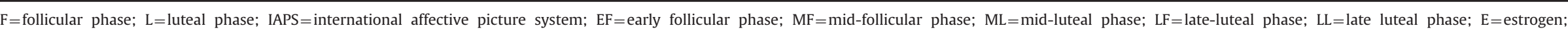
$\mathrm{P}=$ progesterone; $\mathrm{LH}=$ luteinizing hormone, $\mathrm{FSH}=$ follicle-stimulating hormone; $\mathrm{d}=$ day, prog= correct measurement in luteal phase/previous ovulation was assessed based on progesterone assays.

a That revealed significant results for the whole brain. 
progesterone variation across the menstrual cycle influence human and animal brain function related to a variety of psychological processes. Several studies reported functional brain differences across the female menstrual cycle, but a quantitative synthesis of the neural patterns observed is lacking thus far. Here we report the results of an analysis searching for concordant effects of cycle phase on human brain function. The studies cover a wide range of tasks and paradigms and the exact time points within the cycle phases at which measurements were taken varied across studies. Hence, the present analysis focuses on the investigation of the influence of hormonal states in the follicular and luteal phase of the menstrual cycle across different domains of psychological functioning. Because of the variety of tasks and paradigms used in the studies, specific hypotheses about the overlapping brain regions in the two cycle phases are difficult. Since a great amount of evidence from animal literature points towards hippocampus and amygdala as target regions for estrogen and progesterone action in the brain, we expect medial temporal lobe and amygdala activity to differ between cycle phases across different studies.

\section{Methods}

\subsection{Selection of studies}

Several online electronic databases were searched in December 2013 for functional neuroimaging (fMRI) and positron emission tomography (PET) studies investigating differences across cycle phases that were published until 2013. The search was done using the keywords (menstrual OR cycle) AND (fmri OR magnetic resonance imaging OR PET). The reference lists from all identified articles were searched to identify additional relevant studies. Studies were included when they met all of the following criteria: (a) peak activations reported in Montreal Neurological Institute (MNI) or Talairach space; (b) within-subject comparisons between the follicular and luteal phases of the cycle; (c) both contrasts (follicular > luteal as well as luteal > follicular) tested applying the same threshold; (d) contrasts thresholded with a commonly accepted level of significance (minimum $p<0.05$ corrected for multiple comparisons or $p<0.005$ uncorrected) in a whole brain analysis; (e) at least one statistically significant contrast identifying locations of greater task-related activation in the luteal phase, the follicular phase, or both; (f) sample size larger than 10 participants. Eleven studies met these criteria and were included in the present analysis. Four of these studies reported significant results for both contrasts, two for the luteal phase and five for the follicular phase only (Table 1 ). Three additional studies met all other criteria but did not find significant effects for either of the two cycle phases (criteria e), so were not included in the analysis.

\subsection{Creation of activation likelihood estimation maps}

Activation likelihood estimation (ALE) is a voxel-basedmetaanalytic technique for neuroimaging data implemented in the software package Brainmap GingerALE 2.3 (http://brainmap.org/ ale/; cf. Eickhoff et al., 2009; Laird et al., 2005). The algorithm based on Eickhoff et al. (2009) was used. Ginger ALE identifies areas of statistically significant concordance of brain activity among several independent experiments. We converted coordinates reported in Talairach to MNI space following Lancaster et al. (2007) (tal2icbm). In the approach taken by ALE, localization probability distributions for all foci are modeled as the center of 3D Gaussian functions. The full-width at half-maximum (FWHM) values are based on the number of subjects in the analysis with higher sample sizes leading to lower FWHM values (Eickhoff et al., 2009). The Gaussian distributions are summed across the experiments to generate a map of inter-study consistencies that estimates the likelihood of activation for each voxel, the ALE statistic, as determined by the entire set of studies. The false discovery rate (FDRpID) method was used to correct for multiple comparisons at a significance threshold of $p<0.01$, and the cluster threshold was set to $200 \mathrm{~mm}^{3}$. We included 44 foci from 9 studies and 120 subjects in the follicular > luteal contrast and 30 foci from 6 studies and 89 subjects in the luteal $>$ follicular contrast. Information on the studies included is shown in Table 1.

\section{Results}

Higher activation across the studies during luteal phase compared to the follicular phase was found in the left amygdala/hippocampal complex $\left(-29,-2,-29\right.$; cluster size: $\left.344 \mathrm{~mm}^{3}\right)$. Conversely, higher activation during the follicular phase compared to the luteal phase was found in the right amygdala/hippocampal complex $\left(31,-4,-22\right.$; cluster size: $\left.256 \mathrm{~mm}^{3}\right)$. Two clusters in the anterior cingulate cortex (ACC) showed increased activation in the luteal phase compared to the follicular phase $(8,32,18$; cluster size: $688 \mathrm{~mm}^{3} ; 6,38,2$; cluster size: $336 \mathrm{~mm}^{3}$ ) as well as the right temporal pole $\left(40,6,-35\right.$; cluster size: $\left.448 \mathrm{~mm}^{3}\right)$ and one cluster in the left superior temporal gyrus in the reverse contrast $(-63$, $-37,23$; cluster size: $616 \mathrm{~mm}^{3}$ ) (all $p<0.01$; FDR corrected; see Fig. 1 and Supplementary Fig. 1).

\section{Discussion}

The present analysis used ALE in order to investigate concordant brain activation in the follicular and luteal phase of the menstrual cycle across different fMRI paradigms. Lateralized amygdala/hippocampal activity was found during both the follicular and the luteal phase of the cycle. During the follicular phase,

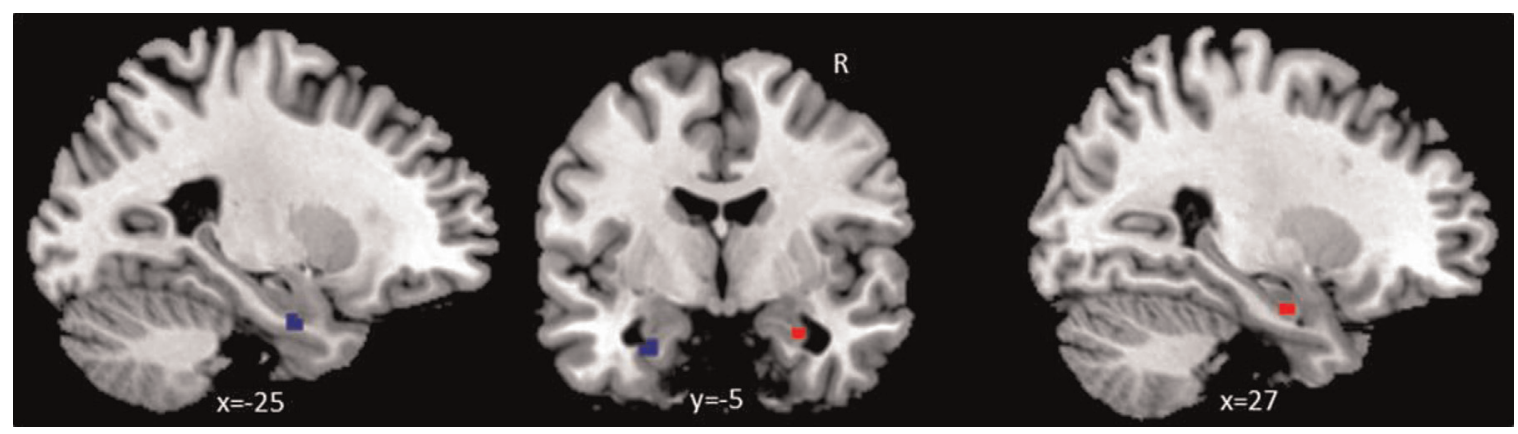

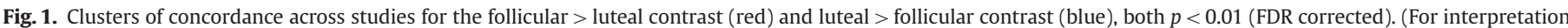
of the references to color in this figure legend, the reader is referred to the web version of this article.) 
the right amygdala/hippocampal complex showed higher neural activity compared to the luteal phase. During the luteal phase, the left amygdala/hippocampal complex showed higher neural activity compared to the follicular phase. Additionally, the ACC and right temporal pole showed greater activation during the luteal phase and the left superior temporal gyrus (STG) during the follicular phase. The results are based on 11 studies and should therefore be interpreted as preliminary evidence for concordant brain activity in different cycle phases. It is important to notice that the effect cannot be attributed to estrogen or progesterone alone and may be dependent on the interplay of both hormones.

Our results suggest that the amygdala/hippocampal complex activation is sensitive to the hormonal changes during the menstrual cycle in women. Over the range of cognitive paradigms and stimulus categories that were included in the present analysis, activity in the right and the left amygdala/hippocampal system varies in opposing directions according to phase, indicating hormonal influences on neural activity in these regions. This is in line with previous findings showing that estrogen and progesterone levels are associated with variations in the structure and function of the amygdala and the hippocampus. A multitude of animal studies found direct effects of estrogen variations on the hippocampus and the amygdala (Pawluski et al., 2009; Shughrue and Merchenthaler, 2000; Tanapat et al., 1999; Woolley and McEwen, 1993; Woolley et al., 1996; Woolley, 1998; Yankova et al., 2001). Not all of these studies investigated naturally occurring fluctuations of hormones over the menstrual or estrous cycle, but rather manipulated the estrogen concentration experimentally and therefore may have resulted in larger effects. Both brain structures, the hippocampus as well as the amygdala, have ovarian hormone receptors in humans and hence can be modulated directly by hormonal activity (Österlund and Hurd, 2001; Sarrieau et al., 1986).

The results of our analysis are consistent with the differences in amygdala activity between follicular and luteal phase reported by Gingnell et al. (2012). The left amygdala of the healthy control subjects was more strongly activated during the luteal phase (Gingnell et al., 2012). Similarly, Derntl et al. (2008) found that neutral faces only activated the left amygdala during the luteal phase. Both studies have not been included in the present quantitative analysis since they only reported region-of-interest based analyses. The present results also parallel several structural MR studies demonstrating menstrual-related changes in volume with higher volumes of the right hippocampus, fusiform gyrus, and parahippocampal gyrus during the follicular compared to the luteal phase (Protopopescu et al., 2008; Pletzer et al., 2010) and greater volume of the left amygdala during the luteal phase compared to the follicular phase (Ossewaarde et al., 2011).

The direction of the observed lateralization effect in the amygdala/hippocampal complex fits very well with previously described behavioral differences in performance of spatial and verbal tasks between the follicular and luteal phase in women. When looking at differential functions associated with right or left hippocampus it has been suggested that the left hippocampus is related to verbal memory processing and the right to spatial processing (Burgess et al., 2002; Saling et al., 1993). Given the pattern of increased verbal memory performance during the luteal phase and increased spatial performance during follicular phase of the cycle, this pattern could be ascribed to differences in right and left hippocampal activation in the different cycle phases although the directionality of the effect clearly cannot be determined. Apart from this broad distinction of hippocampal function, there are more links between lateralized processes in the observed structures and behavioral differences across the cycle associated with these processes. Performance differences across the cycle in spatial abilities for instance could be based on different navigation strategies used to solve the task. Again, lateralization of hippocampal activation is linked to different navigation strategies. An egocentric strategy has been found to be related to left hippocampal activity, whereas an allocentric strategy has been associated with right hippocampal activity (Iglói et al., 2010). In some spatial tasks an allocentric reference frame might be beneficial (e.g., Wiener et al., 2013) and in these tasks better performance during the follicular phase would be in line with greater right lateralization of hippocampal activity in that phase. In rodents, strategy variations have been found to be associated to variations in estrogen concentration over the menstrual cycle (Korol and Kolo, 2002; Qiu et al., 2013). It appears promising to further pursue this line of research by taking a closer look at cycle-dependent strategy variations in women and how they are linked to hormone-related lateralization differences in the medial temporal lobe. In the amygdala, lateralization of activity has been linked to stimulus type and temporal dynamics or habituation rates (Costafreda et al., 2008; Sergerie et al., 2008), but the picture is less clear. A systematic review specifically conducted to investigate the lateralization of amygdala activity by Baas et al. (2004) did not reveal consistent differences in right and left amygdala activity related to stimulus type or habituation. In the reviews by Costafreda et al. (2008) and Baas et al. (2004) possible influences of hormonal variation in the female cycle are not mentioned at all. However, Sergerie et al. (2008) discuss that the differences in amygdala activity over the menstrual cycle could confound the sex-differences they report for amygdala activity. The present result supports this assumption and raises the need for further investigation of the inconsistent literature on amygdala lateralization in the light of female cycle-related lateralization differences.

When looking at the between-subject level, differences in lateralization of brain activity in the amygdala and hippocampus have been related to sex differences. Right amygdala activity has been found to be higher in men and left amygdala activity in women. This pattern emerges for example during emotional face perception in male and female adolescents (Schneider et al., 2011) or the memory for arousing emotional stimuli, that could be associated with activity of the right amygdala in men and the left amygdala in women (Cahill et al., 2004; Canli et al., 2002). Frings et al. (2006) found a similar sex-based lateralization effect for the hippocampus. While performing a spatial memory task, women activated the left hippocampus more than the right hippocampus, whereas the opposite was true for men (Frings et al., 2006). The sex-differences in lateralization of amygdala and hippocampal activity are in line with the results of the present analysis. During the follicular phase, the concentration of female hormones, namely estrogen and progesterone, is low and performance on tasks in which men tend to outperform women is typically increased (Voyer et al., 1995). This is consistent with the current results, which show that the amygdala/hippocampus activation pattern in women is more similar to men during the follicular phase of the menstrual cycle. On the other hand, the pattern found during the luteal phase, when female hormone concentration is higher, resembles the pattern of women in studies comparing male and female brain activation.

Besides the amygdala/hippocampal complex, we found consistent activation in the ACC and right temporal pole in the luteal phase and the STG in the follicular phase across the studies. Interestingly, all three regions have been found to connect to hippocampal regions (Fanselow and Dong, 2010; Kahn et al., 2008; Zhang and Ekstrom, 2012). With regard to psychological functions, the STG is involved in spatial navigation (Zhang and Ekstrom, 2012), the temporal pole in emotional processing (Olson et al., 2007) and the ACC plays an important role in attention regulation of cognitive as well as affective processing (Bush et al., 2000). In the cognitive domain, this regulative role of the ACC is visible in 
tasks that afford error-monitoring and performance-monitoring (Bush et al., 2000). In the affective domain, the function of the ACC has been related to processing of emotional stimuli and mood disorders (Devinsky et al., 1995; Drevets et al., 2008). Two common sources of mood disturbances among women in reproductive age are the premenstrual syndrome and premenstrual dysphoric disorder whose symptoms are present during the luteal phase of the menstrual cycle only (Freeman, 2003). It is likely that the previously observed behavioral differences in women across the menstrual cycle in mood, spatial abilities and emotional processing are underpinned by the variation in neural activity we report in our analysis. Further evidence for hormonal influence on those brain regions was found in studies looking at sex differences and estrogen receptor density. The ACC has a relatively high estrogen receptor density during critical periods of development and was found to be sexually dimorphic in its size with higher volumes in women (which has also been found for the temporal pole; Goldstein et al., 2001; Paus et al., 1996). In the temporal lobe, sex differences with regard to functional lateralization were observed during language processing, with higher left lateralized activity of the STG and other temporal regions in men and bilateral activity in women (Kansaku et al., 2000). However, in light of our results, the cycle phase of the participating women has to be considered as a possible confound, since it was not controlled in that study.

Aside from interpreting changes within individual brain regions across the menstrual cycle, the results of the present analysis could also represent network activity changes across the cycle. Since there is not only a single brain region showing greater activity during one of the two phases, but different regions are higher activated in the same phase, altered functional connectivity and network-level activity in different cycle phases could be an additional explanation. Changes in baseline neuronal activity and connectivity of the female brain across the cycle have been investigated in some recent neuroimaging studies. Alpha frequency was found to be negatively correlated with estrogen, and being significantly lower in the late, compared to the early follicular and luteal phase (Brötzner et al., 2014). Comparable to that, decreased functional connectivity was observed during the luteal phase when compared to the follicular phase in resting-state activity (Petersen et al., 2014; but see Hjelmervik et al. (2014)). Although the present investigation did not include resting-state paradigms, these above mentioned findings may suggest a functional relation of STG activity with right hippocampal activity during the follicular phase, maybe due to increased baseline activity, whereas the ACC and TP may be influenced in their activity themselves by the high hormonal levels in the luteal phase.

To sum up the present results may be taken to indicate that sex differences in task-related activation of the amygdala/hippocampal complex are driven, to some degree at least, by the presence of women who happen to be in the luteal phase of the menstrual cycle when participating in the experiment. Hence, we strongly recommend routinely assessing the cycle phase in behavioral and imaging experiments especially when using tasks that are known to critically involve the amygdala/hippocampal complex. We expect reduced sex differences in performance and patterns of amygdala/hippocampal activation when women are examined during the follicular phase than during the luteal phase. When a sufficient number of imaging studies on menstrual cycle differences applying between-subject designs accumulated, we recommend replicating our analysis with those studies, since all included studies in the present analysis used within-subject designs. Differential interaction of brain activity in specific cycle phases with task-characteristics (such as practice effects) might be addressed with the comparison of those two designs, because they will most likely only influence within-subject analyses. Unfortunately, the current data does as well not allow analyses on the influence of age on our findings. The subjects of the fMRI studies so far were predominantly young women (aged between 20 and 35). It would be interesting to assess the hormonal influences on brain function in different ages in the future. Given that the menstrual cycle changes with age (Lee et al., 1988; Sherman et al., 1976), it is likely that the corresponding brain activity patterns shift as well.

\section{Limitations}

For at least four reasons, the results of the present analysis need to be interpreted with caution. First, the number of studies included in the present analysis is small, with only 11 studies meeting all the inclusion criteria. Second, the present analysis is biased because studies reporting null findings were not included in the analysis, due to restrictions of the ALE method. There were three published studies that did not reveal significant effects (i.e. significantly different activation of functional brain activity between luteal and follicular phase of the cycle). It is of course likely that more studies did not find effects but were not published, a phenomenon that has been termed the file-drawer problem. Third, the analysis included studies with different paradigms, which of course have a strong impact on the activated brain regions in the cycle contrasts. The existing literature does not allow to analyze the studies in more homogenous groups. This is recommended for future analyses, when a larger pool of studies exists. Fourth, the included studies measured participants at slightly different times during the two phases (including early and late follicular phase measurements) and not all studies assessed presence of ovulation before the luteal phase measurement. For these reasons the present results should be carefully interpreted as a first attempt to summarize existing findings on differential brain activity across the female menstrual cycle. The current investigation is not able to answer the question whether cycle-phase related differences in behavioral strategies used to solve the same task are the reason or consequence of the observed lateralization differences.

\section{Conclusion}

In summary, the results of the present analysis indicate a lateralization of task-related neural activity in the amygdala/hippocampal complex when comparing the luteal and follicular phase of the human female menstrual cycle. In line with previously observed sex differences and performance variation across the cycle, the right hemisphere showed higher activity in the follicular phase than in the luteal phase, whereas the reverse was true for the left hemisphere, which showed higher activity in the luteal phase than in the follicular phase. Despite its limitations, the results of the present analysis clearly suggest that cycle phase should be taken into account when conducting neuroimaging research with female participants.

\section{Acknowledgments}

Nina Lisofsky has been a pre-doctoral fellow of the International Max Planck Research School on the Life Course (LIFE, www. imprs-life.mpg.de; participating institutions: MPI for Human Development, Freie Universität Berlin, Humboldt-Universität zu Berlin, University of Michigan, University of Virginia, University of Zurich). None of the authors report a conflict of interest. 


\section{Appendix A. Supplementary material}

Supplementary data associated with this article can be found in the online version at http://dx.doi.org/10.1016/j.neuropsychologia. 2014.12.005.

\section{References}

Amin, Z., Epperson, C.N., Constable, R.T., Canli, T., 2006. Effects of estrogen variation on neural correlates of emotional response inhibition. Neurolmage 32 (1), 457-464. http://dx.doi.org/10.1016/j.neuroimage.2006.03.013.

Andreano, J.M., Cahill, L., 2010. Menstrual cycle modulation of medial temporal activity evoked by negative emotion. NeuroImage 53 (4), 1286-1293. http://dx. doi.org/10.1016/j.neuroimage.2010.07.011.

Baas, D., Aleman, A., Kahn, R.S., 2004. Lateralization of amygdala activation: a systematic review of functional neuroimaging studies. Brain Res. Brain Res. Rev. 45 (2), 96-103. http://dx.doi.org/10.1016/j.brainresrev.2004.02.004.

Bannbers, E., Gingnell, M., Engman, J., Morell, A., Comasco, E., Kask, K., Sundström Poromaa, I., 2012. The effect of premenstrual dysphoric disorder and menstrual cycle phase on brain activity during response inhibition. J. Affect. Disord., 4-7. http://dx.doi.org/10.1016/j.jad.2012.04.006.

Brötzner, C.P., Klimesch, W., Doppelmayr, M., Zauner, A., Kerschbaum, H.H., 2014. Resting state alpha frequency is associated with menstrual cycle phase, estradiol and use of oral contraceptives. Brain Res. 1577, 36-44. http://dx.doi.org/ 10.1016/j.brainres.2014.06.034.

Burgess, N., Maguire, E., O'Keefe, J., 2002. The human hippocampus and spatial and episodic memory. Neuron 35, 625-641 (Retrieved from).

Bush, G., Luu, P., Posner, M., 2000. Cognitive and emotional influences in anterior cingulate cortex. Trends Cogn. Sci. 4 (6), 215-222 (Retrieved from).

Cahill, L., Uncapher, M., Kilpatrick, L., Alkire, M.T., Turner, J., 2004. Sex-related hemispheric lateralization of amygdala function in emotionally influenced memory: an FMRI investigation. Learn. Mem. 11 (3), 261-266. http://dx.doi.org/ 10.1101/lm.70504.

Canli, T., Desmond, J.E., Zhao, Z., Gabrieli, J.D.E., 2002. Sex differences in the neural basis of emotional memories. Proc. Natl. Acad. Sci. USA 99 (16), 10789-10794. http://dx.doi.org/10.1073/pnas.162356599.

Choi, J., Park, S., Kim, Y., Shin, Y., 2006. Different brain activation patterns to pain and pain-related unpleasantness during the menstrual cycle. Anesthesiology 105 (1), 120-127 (Retrieved from).

Costafreda, S.G., Brammer, M.J., David, A.S., Fu, C.H.Y., 2008. Predictors of amygdala activation during the processing of emotional stimuli: a meta-analysis of 385 PET and fMRI studies. Brain Res. Rev. 58 (1), 57-70. http://dx.doi.org/10.1016/j. brainresrev.2007.10.012.

Craig, M.C., Fletcher, P.C., Daly, E.M., Rymer, J., Brammer, M., Giampietro, V., Murphy, D.G.M., 2008. Physiological variation in estradiol and brain function: a functional magnetic resonance imaging study of verbal memory across the follicular phase of the menstrual cycle. Hormon. Behav. 53 (4), 503-508. http: //dx.doi.org/10.1016/j.yhbeh.2007.11.005.

Derntl, B., Windischberger, C., Robinson, S., Lamplmayr, E., Kryspin-Exner, I., Gur, R. C., Habel, U., 2008. Facial emotion recognition and amygdala activation are associated with menstrual cycle phase. Psychoneuroendocrinology 33 (8) 1031-1040. http://dx.doi.org/10.1016/j.psyneuen.2008.04.014.

Devinsky, O., Morrell, M., Vogt, B., 1995. Contributions of anterior cingulate cortex to behaviour. Brain 118, 279-306 (Retrieved from).

Dietrich, T., Krings, T., Neulen, J., Willmes, K., Erberich, S., Thron, a, Sturm, W., 2001. Effects of blood estrogen level on cortical activation patterns during cognitive activation as measured by functional MRI. Neurolmage 13 (3), 425-432. http: //dx.doi.org/10.1006/nimg.2001.0703.

Drevets, W., Savitz, J., Trimble, M., 2008. The subgenual anterior cingulate cortex in mood disorders. CNS Spectr. 13 (8), 663-681 (Retrieved from).

Dreher, J.-C., Schmidt, P.J., Kohn, P., Furman, D., Rubinow, D., Berman, K.F., 2007. Menstrual cycle phase modulates reward-related neural function in women. Proc. Natl. Acad. Sci. USA 104 (7), 2465-2470. http://dx.doi.org/10.1073/ pnas.0605569104.

Eickhoff, S.B., Laird, A.R., Grefkes, C., Wang, L.E., Zilles, K., Fox, P.T., 2009. Coordinatebased activation likelihood estimation meta-analysis of neuroimaging data: a random-effects approach based on empirical estimates of spatial uncertainty. Hum. Brain Mapp. 30 (9), 2907-2926. http://dx.doi.org/10.1002/hbm.20718.

Endicott, J., 1993. The menstrual cycle and mood disorders. J. Affect. Disord. 29 (23), 193-200 (Retrieved from).

Fanselow, M., Dong, H., 2010. Are the dorsal and ventral hippocampus functionally distinct structures? Neuron 65 (1), 1-25. http://dx.doi.org/10.1016/j.neuron.2009.11.031.Are.

Farage, M.A., Osborn, T.W., MacLean, A.B., 2008. Cognitive, sensory, and emotional changes associated with the menstrual cycle: a review. Arch. Gynecol. Obstet 278 (4), 299-307. http://dx.doi.org/10.1007/s00404-008-0708-2.

Fernández, G., Weis, S., Stoffel-Wagner, B., Tendolkar, I., Reuber, M., Beyenburg, S., Elger, C.E., 2003. Menstrual cycle-dependent neural plasticity in the adult human brain is hormone, task, and region specific. J. Neurosci.: Off. J. Soc. Neurosci. 23 (9), 3790-3795 (Retrieved from).

Fernández, G., Weyerts, H., Schrader-Bölsche, M., Tendolkar, I., Smid, H.G.O.M., Tempelmann, C., Heinze, H.-J., 1998. Successful verbal encoding into episodic memory engages the posterior hippocampus: a parametrically analyzed functional magnetic resonance imaging study. J. Neurosci. 18 (5), 1841-1847 (Retrieved from).

Frank, T.C., Kim, G.L., Krzemien, A., Van Vugt, D.A., 2010. Effect of menstrual cycle phase on corticolimbic brain activation by visual food cues. Brain Res. 1363 , 81-92. http://dx.doi.org/10.1016/j.brainres.2010.09.071.

Freeman E.W., 2003. Premenstrual syndrome and premenstrual dysphoric disorder: definitions and diagnosis. In: Proceedings of the Symposium on Premenstrual Syndrome and Premenstrual Dysphoric Disorders, Rhodes, Greece, July 17, 2000. Psychoneuroendocrinology. 28, 25-37.doi: 10.1016/S0306-4530(03) 00099-4.

Frings, L., Wagner, K., Unterrainer, J., 2006. Gender-related differences in lateralization of hippocampal activation and cognitive strategy. Brain Imaging 17 (4), 417-421 (Retrieved from).

Gingnell, M., Morell, A., Bannbers, E., Wikström, J., Sundström Poromaa, I., 2012. Menstrual cycle effects on amygdala reactivity to emotional stimulation in premenstrual dysphoric disorder. Hormon. Behav. , http://dx.doi.org/10.1016/j. yhbeh.2012.07.005.

Gizewski, E.R., Krause, E., Karama, S., Baars, A., Senf, W., Forsting, M., 2006. There are differences in cerebral activation between females in distinct menstrual phases during viewing of erotic stimuli: a fMRI study. Exp. Brain Res. 174 (1), 101-108. http://dx.doi.org/10.1007/s00221-006-0429-3.

Goldstein, J.M., Jerram, M., Poldrack, R., Ahern, T., Kennedy, D.N., Seidman, L.J., Makris, N., 2005. Hormonal cycle modulates arousal circuitry in women using functional magnetic resonance imaging. J. Neurosci.: Off. J. Soc. Neurosci. 25 (40), 9309-9316. http://dx.doi.org/10.1523/JNEUROSCI.2239-05.2005.

Goldstein, J.M., Seidman, L.J., Horton, N.J., Makris, N., Kennedy, D.N., Caviness, V.S., Tsuang, M.T., 2001. Normal sexual dimorphism of the adult human brain assessed by in vivo magnetic resonance imaging. Cereb. Cortex 11 (6), 490-497 (Retrieved from).

Hampson, E., 1990. Variations in sex-related cognitive abilities across the menstrual cycle. Brain Cogn. 14 (1), 26-43 (Retrieved from).

Hausmann, M., Bayer, U., 2010. Sex hormonal effects on hemispheric asymmetry and interhemispheric interaction. In: Hugdahl, K., Westerhausen, R. (Eds.), The Two Halves of the Brain: Information Processing in the Cerebral Hemispheres. MIT, Cambridge,MA, pp. 253-283.

Hausmann, M., Slabbekoorn, D., Van Goozen, S.H., Cohen-Kettenis, P.T., Güntürkün, O., 2000. Sex hormones affect spatial abilities during the menstrual cycle. Behav. Neurosci. 114 (6), 1245-1250 (Retrieved from).

Hjelmervik, H., Hausmann, M., Osnes, B., Westerhausen, R., Specht, K., 2014. Resting states are resting traits - an FMRI study of sex differences and menstrual cycle effects in resting state cognitive control networks. PLoS One 9 (7), e103492. http://dx.doi.org/10.1371/journal.pone.0103492.

Iglói, K., Doeller, C., Berthoza, A., Rondi-Reig, L., Burgess, N., 2010. Lateralized human hippocampal activity predicts navigation based on sequence or place memory. Proc. Natl. Acad. Sci. USA 107 (32), 14466-14471 (doi:10.1073/ pnas.1004243107/-/DCSupplemental.www.pnas.org/cgi/doi/10.1073/ pnas.1004243107)

Ino, T., Doi, T., Kimura, T., Ito, J., Fukuyama, H., 2004. Neural substrates of the performance of an auditory verbal memory: between-subjects analysis by fMRI. Brain Res. Bull. 64 (2), 115-126. http://dx.doi.org/10.1016/j. brainresbull.2004.04.018.

Kahn, I., Andrews-Hanna, J.R., Vincent, J.L., Snyder, A.Z., Buckner, R.L., 2008. Distinct cortical anatomy linked to subregions of the medial temporal lobe revealed by intrinsic functional connectivity. J. Neurophysiol. 100 (1), 129-139. http://dx. doi.org/10.1152/jn.00077.2008.

Kansaku, K., Yamaura, A., Kitazawa, S., 2000. Sex differences in lateralization revealed in the posterior language areas. Cereb. Cortex 10 (9), 866-872 (Retrieved from).

Konrad, C., Engelien, A., Schöning, S., Zwitserlood, P., Jansen, A., Pletziger, E., Kugel, H., 2008. The functional anatomy of semantic retrieval is influenced by gender, menstrual cycle, and sex hormones. J. Neural Transm. 115 (9), 1327-1337. http: //dx.doi.org/10.1007/s00702-008-0073-0.

Korol, D.L., 2004. Role of estrogen in balancing contributions from multiple memory systems. Neurobiol. Learn. Mem. 82 (3), 309-323. http://dx.doi.org/10.1016/ j.nlm.2004.07.006.

Korol, D.L., Kolo, L.L., 2002. Estrogen-induced changes in place and response learning in young adult female rats. Behav. Neurosci. 116 (3), 411-420. http: //dx.doi.org/10.1037//0735-7044.116.3.411.

Kühn, S., Gallinat, J., 2014. Segregating cognitive functions within hippocampal formation: a quantitative meta-analysis on spatial navigation and episodic memory. Hum. Brain Mapp. 35 (4), 1129-1142. http://dx.doi.org/10.1002/ hbm.22239.

Lacreuse, A., Verreault, M., Herndon, J.G., 2001. Fluctuations in spatial recognition memory across the menstrual cycle in female rhesus monkeys. Psychoneuroendocrinology 26 (6), 623-639 (Retrieved from).

Laird, A.R., Fox, P.M., Price, C.J., Glahn, D.C., Uecker, A.M., Lancaster, J.L., Fox, P.T., 2005. ALE meta-analysis: controlling the false discovery rate and performing statistical contrasts. Hum. Brain Mapp. 25 (1), 155-164. http://dx.doi.org/ 10.1002/hbm.20136.

Lancaster, J.L., Tordesillas-Gutiérrez, D., Martinez, M., Salinas, F., Evans, A., Zilles, K., Fox, P.T., 2007. Bias between MNI and Talairach coordinates analyzed using the ICBM-152 brain template. Hum. Brain Mapp. 28 (11), 1194-1205. http://dx.doi. org/10.1002/hbm.20345.

Lee, S.J., Lenton, E.A., Sexton, L., Cooke, I.D., 1988. The effect of age on the cyclical patterns of plasma $\mathrm{LH}, \mathrm{FSH}$, oestradiol and progesterone in women with regular 
menstrual cycles. Hum. Reprod. 3 (7), 851-855 (Retrieved from).

Maki, P.M., Rich, J.B., Rosenbaum, R.S., 2002. Implicit memory varies across the menstrual cycle: estrogen effects in young women. Neuropsychologia 40 (5), 518-529 (Retrieved from).

McEwen, B.S., Milner, T.A., 2007. Hippocampal formation: shedding light on the influence of sex and stress on the brain. Brain Res. Rev. 55 (2), 343-355. http: //dx.doi.org/10.1016/j.brainresrev.2007.02.006.

Moos, R.H., Kopell, B.S., Melges, F.T., Yalom, I.D., Lunde, D.T., Clayton, R.B., Hamburg, D. a, 1969. Fluctuations in symptoms and moods during the menstrual cycle. J. Psychosom. Res. 13 (1), 37-44 (Retrieved from).

Mordecai, K.L., Rubin, L.H., Maki, P.M., 2008. Effects of menstrual cycle phase and oral contraceptive use on verbal memory. Hormon. Behav. 54 (2), 286-293. http://dx.doi.org/10.1016/j.yhbeh.2008.03.006.

Olson, I.R., Plotzker, A., Ezzyat, Y., 2007. The Enigmatic temporal pole: a review of findings on social and emotional processing. Brain : J. Neurol. 130 (Pt 7), 1718-1731. http://dx.doi.org/10.1093/brain/awm052.

Ossewaarde, L., Hermans, E.J., van Wingen, G.A., Kooijman, S.C., Johansson, I.-M. Bäckström, T., Fernández, G., 2010. Neural mechanisms underlying changes in stress-sensitivity across the menstrual cycle. Psychoneuroendocrinology 35 (1), 47-55. http://dx.doi.org/10.1016/j.psyneuen.2009.08.011.

Ossewaarde, L., van Wingen, G.A., Rijpkema, M., Bäckström, T., Hermans, E.J., Fernández, G., 2011. Menstrual cycle-related changes in amygdala morphology are associated with changes in stress sensitivity. Hum. Brain Mapp. , http://dx.doi. org/10.1002/hbm.21502.

Österlund, M., Hurd, Y., 2001. Estrogen receptors in the human forebrain and the relation to neuropsychiatric disorders. Prog. Neurobiol. 64, 251-267 (Retrieved from).

Paus, T., Otaky, N., Caramanos, Z., MacDonald, D., Zijdenbos, A., D’Avirro, D., Evans, A.C., 1996. In vivo morphometry of the intrasulcal gray matter in the human cingulate, paracingulate, and superior-rostral sulci: hemispheric asymmetries, gender differences and probability maps. J. Comp. Neurol., 376; , pp. 664-673. http://dx.doi.org/10.1002/(SICI)1096-9861(19961223)376:4 < 664::AIDCNE12 > 3.0.CO;2-M.

Pawluski, J.L., Brummelte, S., Barha, C.K., Crozier, T.M., Galea, L.A.M., 2009. Effects of steroid hormones on neurogenesis in the hippocampus of the adult female rodent during the estrous cycle, pregnancy, lactation and aging. Front. Neuroendocrinol. 30 (3), 343-357. http://dx.doi.org/10.1016/j.yfrne.2009.03.007.

Petersen, N., Kilpatrick, L. a, Goharzad, A., Cahill, L., 2014. Oral contraceptive pill use and menstrual cycle phase are associated with altered resting state functional connectivity. NeuroImage 90, 24-32. http://dx.doi.org/10.1016/j. neuroimage.2013.12.016.

Pletzer, B., Kronbichler, M., Aichhorn, M., Bergmann, J., Ladurner, G., Kerschbaum, H.H., 2010. Menstrual cycle and hormonal contraceptive use modulate human brain structure. Brain Res. 1348, 55-62. http://dx.doi.org/10.1016/j. brainres.2010.06.019.

Pletzer, B., Kronbichler, M., Ladurner, G., Nuerk, H.-C., Kerschbaum, H., 2011. Menstrual cycle variations in the BOLD-response to a number bisection task: implications for research on sex differences. Brain Res. 1420, 37-47. http://dx. doi.org/10.1016/j.brainres.2011.08.058.

Protopopescu, X., Butler, T., Pan, H., Root, J., Altemus, M., Polanecsky, M., Stern, E., 2008. Hippocampal structural changes across the menstrual cycle. Hippocampus 18 (10), 985-988. http://dx.doi.org/10.1002/hipo.20468.

Protopopescu, X., Pan, H., Altemus, M., Tuescher, O., Polanecsky, M., McEwen, B., Stern, E., 2005. Orbitofrontal cortex activity related to emotional processing changes across the menstrual cycle. Proc. Natl. Acad. Sci. USA 102 (44) 16060-16065. http://dx.doi.org/10.1073/pnas.0502818102.

Qiu, L.R., Germann, J., Spring, S., Alm, C., Vousden, D.A., Palmert, M.R., Lerch, J.P., 2013. Hippocampal volumes differ across the mouse estrous cycle, can change within 24 hours, and associate with cognitive strategies. Neurolmage $83 \mathrm{C}$. 593-598. http://dx.doi.org/10.1016/j.neuroimage.2013.06.074.

Rasia-Filho, A.A., Fabian, C., Rigoti, K.M., Achaval, M., 2004. Influence of sex, estrous cycle and motherhood on dendritic spine density in the rat medial amygdala revealed by the Golgi method. Neuroscience 126 (4), 839-847. http://dx.doi. org/10.1016/j.neuroscience.2004.04.009.

Romans, S., Clarkson, R., Einstein, G., Petrovic, M., Stewart, D., 2012. Mood and the menstrual cycle: a review of prospective data studies. Gender Med. 9 (5), 361-384. http://dx.doi.org/10.1016/j.genm.2012.07.003.

Roberts, G.M.P., Newell, F., Simões-Franklin, C., Garavan, H., 2008. Menstrual cycle phase modulates cognitive control over male but not female stimuli. Brain Res. 1224, 79-87. http://dx.doi.org/10.1016/j.brainres.2008.05.061.

Rosenberg, L., Park, S., 2002. Verbal and spatial functions across the menstrual cycle in healthy young women. Psychoneuroendocrinology 27 (7), 835-841 (Retrieved from).

Rumberg, B., Baars, A., Fiebach, J., Ladd, M.E., Forsting, M., Senf, W., Gizewski, E.R., 2010. Cycle and gender-specific cerebral activation during a verb generation task using fMRI: comparison of women in different cycle phases, under oral contraception, and men. Neurosci. Res. 66 (4), 366-371. http://dx.doi.org/ 10.1016/j.neures.2009.12.011.

Rupp, H.A., James, T.W., Ketterson, E.D., Sengelaub, D.R., Janssen, E., Heiman, J.R., 2009. Neural activation in the orbitofrontal cortex in response to male faces increases during the follicular phase. Hormon. Behav. 56 (1), 66-72. http://dx doi.org/10.1016/j.yhbeh.2009.03.005.

Saling, M.M., Berkovic, S.F., O’Shea, M.F., Kalnins, R.M., Darby, D.G., Bladin, P.F., 1993. Lateralization of verbal memory and unilateral hippocampal sclerosis: evidence of task-specific effects. J. Clin. Exp. Neuropsychol. 15 (4), 608-618. http://dx.doi. org/10.1080/01688639308402582.

Sarrieau, A., Dussaillant, M., Agid, F., 1986. Autoradiographic localization of glucocorticosteroid and progesterone binding sites in the human post-mortem brain. J. Steroid Biochem. 25 (5), 717-721 (Retrieved from).

Schneider, S., Peters, J., Bromberg, U., Brassen, S., Menz, M.M., Miedl, S.F., Büchel, C. 2011. Boys do it the right way: sex-dependent amygdala lateralization during face processing in adolescents. NeuroImage 56 (3), 1847-1853. http://dx.doi. org/10.1016/j.neuroimage.2011.02.019.

Schöning, S., Engelien, A., Kugel, H., Schäfer, S., Schiffbauer, H., Zwitserlood, P. Konrad, C., 2007. Functional anatomy of visuo-spatial working memory during mental rotation is influenced by sex, menstrual cycle, and sex steroid hormones. Neuropsychologia 45 (14), 3203-3214. http://dx.doi.org/10.1016/j. neuropsychologia.2007.06.011.

Sergerie, K., Chochol, C., Armony, J.L., 2008. The role of the amygdala in emotional processing: a quantitative meta-analysis of functional neuroimaging studies. Neurosci. Biobehav. Rev. 32 (4), 811-830. http://dx.doi.org/10.1016/j. neubiorev.2007.12.002.

Sherman, B.M., Korenman, S.G., 1975. Hormonal characteristics of the human menstrual cycle throughout reproductive life. J. Clin. Investig. 55, 699-706.

Sherman, B.M., West, J.H., Korenman, S.G., 1976. The menopausal transition: analysis of LH, FSH, estradiol, and progesterone concentrations during menstrual cycles of older women. J. Clin. Endocrinol. Metab. 42 (4), 629-636.

Shughrue, P.J., Merchenthaler, I., 2000. Estrogen is more than just a "sex hormone": novel sites for estrogen action in the hippocampus and cerebral cortex. Front. Neuroendocrinol. 21 (1), 95-101. http://dx.doi.org/10.1006/frne.1999.0190.

Silverman, I., Phillips, K., 1993. Effects of estrogen changes during the menstrual cycle on spatial performance. Ethol. Sociobiol. 270, 257-269 (Retrieved from).

Spencer, J.L., Waters, E.M., Romeo, R.D., Wood, G.E., Milner, T.A., McEwen, B.S., 2008 Uncovering the mechanisms of estrogen effects on hippocampal function. Front. Neuroendocrinol. 29 (2), 219-237. http://dx.doi.org/10.1016/j. yfrne.2007.08.006.

Stackman, R.W., Blasberg, M.E., Langan, C.J., Clark, A.S., 1997. Stability of spatial working memory across the estrous cycle of Long-Evans rats. Neurobiol. Learn. Mem. 67 (2), 167-171. http://dx.doi.org/10.1006/nlme.1996.3753.

Tanapat, P., Hastings, N.B., Reeves, A.J., Gould, E., 1999. Estrogen stimulates a transient increase in the number of new neurons in the dentate gyrus of the adult female rat. J. Neurosci. 19 (14), 5792-5801 (Retrieved from).

Voyer, D., Voyer, S., Bryden, M., 1995. Magnitude of sex differences in spatial abilities: a meta-analysis and consideration of critical variables. Psychol. Bull. 117 (2), 250-270 (Retrieved from).

Weis, S., Hausmann, M., Stoffers, B., Sturm, W., 2011. Dynamic changes in functional cerebral connectivity of spatial cognition during the menstrual cycle. Hum. Brain Mapp. 32 (10), 1544-1556. http://dx.doi.org/10.1002/hbm.21126.

Weis, S., Hausmann, M., Stoffers, B., Vohn, R., Kellermann, T., Sturm, W., 2008. Estradiol modulates functional brain organization during the menstrual cycle: an analysis of interhemispheric inhibition. J. Neurosci. 28 (50), 13401-13410. http: //dx.doi.org/10.1523/JNEUROSCI.4392-08.2008.

Wiener, J.M., de Condappa, O., Harris, M.A., Wolbers, T., 2013. Maladaptive bias for extrahippocampal navigation strategies in aging humans. J. Neurosci. : Off. J. Soc. Neurosci. 33 (14), 6012-6017. http://dx.doi.org/10.1523/JNEUROSCI.071712.2013.

Woolley, C.S., 1998. Estrogen-mediated structural and functional synaptic plasticity in the female rat hippocampus. Hormon. Behav. 34 (2), 140-148. http://dx.doi. org/10.1006/hbeh.1998.1466.

Woolley, C.S., McEwen, B.S., 1993. Roles of estradiol and progesterone in regulation of hippocampal dendritic spine density during the estrous cycle in the rat. J. Comp. Neurol. 336 (2), 293-306. http://dx.doi.org/10.1002/cne.903360210.

Woolley, C.S., Weiland, N.G., McEwen, B.S., Schwartzkroin, P.A., 1997. Estradiol increases the sensitivity of hippocampal CA1 pyramidal cells to NMDA receptormediated synaptic input: correlation with dendritic spine density. J. Neurosci.: Off. J. Soci. Neurosci. 17 (5), 1848-1859 (Retrieved from).

Woolley, C.S., Wenzel, H.J., Schwartzkroin, P.A., 1996. Estradiol increases the frequency of multiple synapse boutons in the hippocampal CA1 region of the adult female rat. J. Comp. Neurol. 373 (1), 108-117. http://dx.doi.org/10.1002/(SICI) 1096-9861(19960909)373:1 < 108::AID-CNE9 > 3.0.CO;2-8.

Yankova, M., Hart, S.A., Woolley, C.S., 2001. Estrogen increases synaptic connectivity between single presynaptic inputs and multiple postsynaptic CA1 pyramidal cells: a serial electron-microscopic study. Proc. Natl. Acad. Sci. USA 98 (6), 3525-3530. http://dx.doi.org/10.1073/pnas.051624598.

Zhang, H., Ekstrom, A., 2012. Human neural systems underlying rigid and flexible forms of allocentric spatial representation. Hum. Brain Mapp. , http://dx.doi. org/10.1002/hbm.21494. 